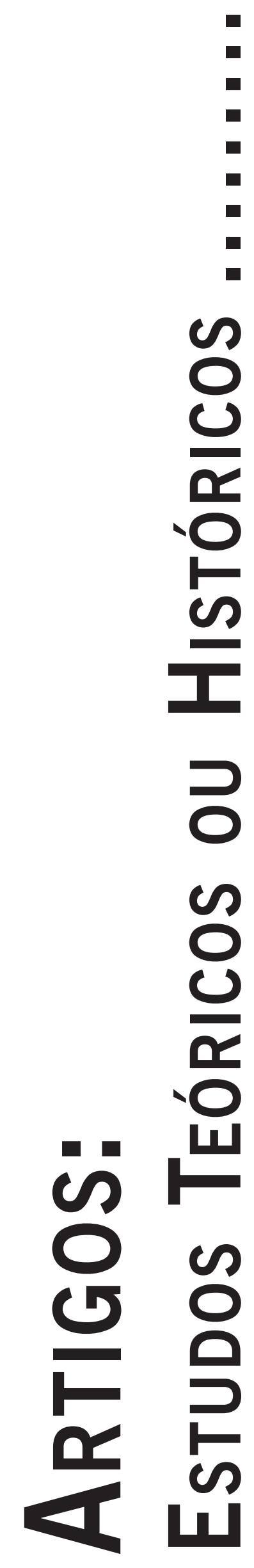




\title{
A CONSTRUÇÃO DO SER MULHER NA AGRICULTURA FAMILIAR: UMA PERSPECTIVA LOGOTERAPÊUTICA
}

\author{
The Construction of Being a Woman in Family Farming: a Logotherapeutic Perspective
}

La Construcción del Ser Mujer en la Agricultura Familiar: una Perspectiva Logoterapéutica

Franchesca Carolina Baronio

LUCIENE GEIGER

\begin{abstract}
Resumo: Este trabalho buscou investigar a relação do "ser mulher" no contexto da agricultura familiar a partir de uma perspectiva logoterapêutica desenvolvida pelo austríaco Viktor Emil Frankl. Por meio de uma revisão narrativa de caráter qualitativo, buscou-se definir o perfil do Ser Mulher na agricultura familiar com o descritor "mulheres rurais" nas bases de dados Biblioteca Virtual em Saúde (BVS) e Biblioteca Digital de Teses e Dissertações (BDTD). Foram utilizados materiais do período de publicação do ano de 2011 a 2016. Os materiais foram analisados por meio de análise de conteúdo resultando em duas categorias. Em ”Ser mulher: uma construção autoral ou um destino a cumprir", identifica-se o ser mulher vinculado aos papeis de mãe, esposa e cuidadora, fruto de uma construção social. Por sua vez, "Mulheres agricultoras: sobre trabalho e parentalidade" trata das formas de trabalho não valorizadas vinculadas ao ser mãe e esposa. A partir do referencial da Logoterapia pode-se entender como constroem sentidos de vida e as alternativas de uma liberdade de sentido para uma escolha autêntica que promova saúde. A partir dessa compreensão, esperou-se possibilitar ao profissional da saúde reflexões que vislumbrem alternativas de intervenções logoterapêuticas para promoção de saúde e de existências mais plenas de sentido.
\end{abstract}

Palavras-chave: Mulheres agricultoras; Logoterapia; Sentido de Vida.

\begin{abstract}
This work investigated how "being a woman" is cinstructed in the context of family farming from a logotherapeutic perspective developed by the austrian Viktor Emil Frankl. Through a qualitative narrative review, it was sought to define the profile of "being a woman" in family farming with the descriptor "rural women" in the databases Virtual Health Library (BVS) andBiblioteca Digital de Teses e Dissertações (BDTD). Materials published from 2011 to 2016 were used and analyzed by content analysis resulting in two categories. "Being a woman: an authorial construction or a destiny to fulfill" identifies the construction of being a woman tied to the roles of mother, wife and caregiver, resulted from a social construction. In turn, "Women farmers: work and parenting" approaches undervalued types of work related to being a mother and wife. From the referencial of Logoterapy it can be understood how they find meanings of life and the alternatives of a freedom of meaning for an authentic choice that promotes health. From this understanding, we hope to promote reflections to health professionals to envisage alternative logotherapeutic interventions to promote health and more meaningful lives.
\end{abstract}

Keywords: Rural women; Logotherapy; Meaning of Life.

Resumen: Este trabajo busca investigar la relación del "ser mujer" en el contexto de la agricultura familiar a partir de una perspectiva logoterapéutica, desarrollada por el austríaco Viktor Emil Frankl. Por medio de una revisión narrativa de carácter cualitativo, se buscó definir el perfil del Ser Mujer en la agricultura familiar, con la expresión "mujeres rurales" en las bases de datos Biblioteca Virtual em Saúde (BVS) y la Biblioteca Digital de Teses e Dissertações (BDTD). Fueron utilizados materiales con publicación en el periodo de 2011 a 2016. Los mismos fueron analizados por medio de su contenido, resultando en dos categorías. En "Ser mujer: una construcción autoral o un destino a cumplir" se identifica el ser mujer vinculado a los papeles de madre, esposa y cuidadora, fruto de una construcción social. Por otro lado, "Mujeres agricultoras: sobre trabajo y la crianza de los hijos" trata de las formas de trabajo no valorizadas vinculadas al ser madre y esposa. A partir del paradigma de la Logoterapia se puede entender como se construyen sentidos de vida y las alternativas de una libertad de sentido para una elección auténtica que promueva salud. A partir de esta comprensión, se espera posibilitar que los profesionales de la salud reflexionen y vislumbren alternativas de intervenciones logoterapéuticas para promoción de salud y de existencias más llenas de sentido

Palabras-clave: Mujeres agricultoras; Logoterapia; Sentido de Vida.

\section{Introdução}

"O ser humano é capaz de mudar o mundo para melhor, se possível, e de mudar a si mesmo para melhor, se necessário"

(Viktor E. Frankl, Em Busca de Sentido)
A agricultura familiar, compreendida como uma forma de produção agrária em menor escala, com alternativas de trabalho mais manuais e artesanais, utilização de mão de obra basicamente familiar ou de grupos de convívio da vizinhança e amigos, tem sido fonte de produção e movimentação de capital social (Gonçalves \& Vital, 2014). Em decorrência disso, movimenta implicações na elaboração de políticas públicas para a sua garantia e manutenção 
(Gonçalves \& Vital, 2014; Salvaro, Lago \& Wolf, 2013). Primeiramente, deve-se esclarecer que a agricultura familiar é, conforme os autores, um cenário no qual o trabalho se dá basicamente através da força familiar e comunitária. A partir disso, a discussão a respeito dos papéis de gênero e suas devidas ocupações vem sendo tema de diversas publicações a respeito desse panorama. (Lassak, 2010; Nogueira \& Toneli, 2016; Pinto et. al., 2013).

Historicamente podemos identificar uma evolução do ser mulher através dos estudos científicos que trazem a discussão de gênero para reflexão. O que se pode perceber é que a partir do século XIX, a diferença entre ser mulher e ser homem era evidenciada em seus papéis sociais e de poder e, segundo a autora, essa teoria era reforçada com uma justificativa biológica de que seus corpos eram diferentes e complementares: o homem servia para ocupar espaços públicos e a mulher estava destinada aos afazeres do lar (Pinto, 2005). Para as mulheres do campo ou agricultoras, o construto "ser mulher" é reforçado por um atravessamento "teológico"1 um tanto determinista, ficando seu papel social definido desde a infância como filha, mãe de família, reprodutora e doméstica (Lassak, 2010). Dessa forma, o ser mulher somente passa a ser reconhecido pela maternidade e pelo matrimônio (Pinto, 2005).

A partir dos anos 1970 e o avanço dos estudos feministas, essa visão determinista sobre ser mulher começa a ser amplamente questionada, resultando numa nova concepção do conceito como uma construção, ou seja, "[...] é consequência de uma extensa e intrincada rede de significações sociais” (Pinto, 2005, p. 14). A partir de então, abordar "a mulher" seria restringir-se ao biológico e, supostamente, universal, enquanto que ao se referir "às mulheres" se estaria atentando para a possibilidade de construção que cada mulher pode fazer da sua existência, apontando para o respeito à diversidade de vivências a despeito de papéis predeterminados, conforme abordam os estudos feministas (Pilar, 2013), mas também para a possibilidade de liberdade de escolha e de autoria do próprio destino, conforme a Logoterapia.

A Logoterapia, fundada pelo psiquiatra e neurologista austríaco Viktor Emil Frankl, também conhecida como Psicoterapia do Sentido da Vida e considerada a terceira escola vienense de psicoterapia, tem como objeto de estudo o sentido da vida (Kraus, Rodrigues \& Dixe, 2009). Segundo Frankl, (2008), essa terapia tem como objetivo principal auxiliar a pessoa a encontrar um sentido em sua vida. Num processo particular de construção através da análise existencial, a pessoa é colocada como ser responsável diante do sentido de sua vida, sendo o terapeuta um facilitador desse processo (Xausa, 1986; Kraus et al., 2009).

Tendo sido prisioneiro de campos de concentração durante a época do nazismo na Alemanha e perdido sua

\footnotetext{
A utilização da palavra "teológico" foi escolhida por ser assim citada na obra referenciada. Com a intenção de ser a citação mais fidedigna, optamos por assim mantê-la.
}

família e seus bens, Viktor E. Frankl pôde experienciar o sofrimento e o desejo de sobreviver e, por meio do contato com outras tantas pessoas naquele contexto, agarrou-se à possibilidade de estudá-las como forma de se manter lutando por sua vida (Xausa, 1986). Após sua libertação, Frankl veio a publicar sua autobiografia "Em busca de sentido" na qual relata sua experiência como um movimento que impulsionou a escrita do livro "Em busca de Sentido", importante publicação para o desenvolvimento da Logoterapia (Frankl, 2008) e sua consequente compreensão do ser humano.

Somando-se a essa questão, tem-se o fato de que ao longo da existência cada pessoa pode passar por diversas mudanças, algumas das quais podem levá-la ao sofrimento. Para mulheres, a perda e a separação de familiares e amigos, doenças crônicas e o processo de envelhecimento, a saída dos filhos de casa, entre outras, podem se constituir em fontes de sofrimento. Conforme aponta um estudo transversal realizado na Serra Gaúcha com trabalhadores da agricultura familiar (Faria et. al., 1999), a saída dos filhos e o consequente esvaziamento dos lares de casa constitui um fator importante observado na prevalência de morbidade psiquiátrica.

Nesse contexto, no qual delas ainda é esperado o papel de cuidadoras, a responsabilidade de educar os filhos, cuidar da casa e do marido (Pinto, 2005), pode-se pensar o quanto o sentido de vida das mulheres pode ser afetado com a saída de seus filhos ou a perda de seus companheiros, significando a perda de um papel social sobre o qual se construiu um sentido de vida. Cita-se uma passagem escrita por Natalie Rogers "Uma importante parte de mim, de minha identidade não é mais necessária. E a necessidade de ser necessária representa uma parte importante da identidade da maioria das mães" (1993, p. 41). Nesse trecho de sua autobiografia em que retrata como foi a separação e a saída de casa, a autora exemplifica como para ela o ser mãe é constituidor de um sentido de vida e como essa ausência é carregada da necessidade de ressignificar os sentidos. Lidar com tais mudanças remete diretamente ao questionamento quanto à possibilidade de encontrar novos sentidos de vida.

Há ainda as mulheres que questionam ou mesmo que simplesmente não vivenciam alguns dos papéis tipicamente convencionados para serem desempenhados por mulheres, como casar-se, ser mãe e cuidar do lar, que por vezes enfrentam resistências e questionamentos constantes sobre ser mulher. Entendendo esses questionamentos como adversidades na adultez, é necessário refletir sobre a perspectiva do sentido de vida como alternativa de enfrentamento e promoção de saúde (Sommerhalder, 2010). Pois Frankl (2008) afirma que, apesar de todo o sofrimento e dificuldade em sua trajetória, o ser humano é capaz de encontrar um sentido para sua existência, considerando que qualquer situação em sua vida possa se tornar um caminho para a vontade de sentido. 
Assim, este estudo busca compreender o ser mulher desde uma perspectiva logoterapêutica, identificando como sentidos de vida podem estar relacionados com os modos de ser mulher e como podem ser reconstruídos ao longo da vida. A partir dessa articulação teórica e seus achados, buscar-se-á refletir sobre quem são e como vivem essas mulheres da agricultura familiar e através da Logoterapia tecer reflexões que possam auxiliar na construção de sua saúde e qualidade de vida.

\section{Método}

Para a produção deste estudo, de caráter qualitativo e constituído de uma revisão bibliográfica narrativa, foi realizada uma pesquisa nas bases de dados Biblioteca Virtual em Saúde (BVS) e Biblioteca Digital de Teses e Dissertações (BDTD). Inicialmente não foi encontrado nenhum material que relacionasse Logoterapia à construção do Ser Mulher. A partir disso, optou-se por realizar uma busca para delinear o perfil das mulheres rurais, sendo utilizada a palavra-chave "mulheres rurais". Foram consideradas somente publicações em texto completo de 2011 até 2016 em língua portuguesa, e foram descartados materiais duplicados e que não abordassem em seus títulos e resumos as temáticas de gênero ou planejamento de vida no contexto da agricultura familiar. No final resultando em 18 publicações na BDTD e 8 artigos na BVS. Ao final, após a leitura dos resumos foram selecionadas 6 produções.

O procedimento escolhido para a análise dos materiais foi a análise de conteúdo conforme Bardin (2009), caracterizada como um conjunto de técnicas de análise de comunicações que utiliza procedimentos sistemáticos e objetivos de descrição de seu conteúdo, permitindo inferências de conhecimentos por meio de pré-análise, exploração do material e tratamento dos resultados, com inferência e interpretação. Primeiramente, na pré-análise, por meio de uma exaustiva leitura flutuante, tomou-se contato com os materiais a serem investigados, selecionando aqueles que estavam de acordo com os objetivos deste trabalho. Na segunda etapa, exploração do material, os dados foram organizados nas categorias que emergiram, a saber, "Ser mulher: uma construção autoral ou um destino a cumprir?" e "Mulheres agricultoras: Sobre o trabalho e parentalidade". Por fim, na terceira fase, que se refere à interpretação, foram realizadas inferências com base no referencial teórico logoterapêutico. A construção das mesmas, por diversos trechos, parece se cruzar, visto que na realidade o papel de ser mulher, engloba a parentalidade e o "auxílio" nas atividades da família, sem ter uma grande divisão ou clareza desse espaço. Entretanto, com a intenção de dar visibilidade a essas mulheres, optou por criar duas categorias distintas, mas que por vezes dialogam e se complementam. Para realizar uma compreensão dos dados oriundos dessa análise, foi utilizado o referencial teórico da Logoterapia.

\section{Resultados}

\section{Ser mulher: uma construção autoral ou um destino a cumprir?}

A partir das obras pesquisadas sobre o gênero e ruralidade, entende-se que construção do ser mulher, para além de uma questão biológica de diferenciação entre macho e fêmea, é uma construção pessoal e social que nos torna pessoas e mulheres (Geiger, 2014), e no caso das mulheres rurais, esta construção é influenciadas pela família, vizinhança e os espaços limitados em que elas circulam (Maia \& Sant'ana, 2011). Apesar de pequenos avanços no decorrer dos anos da luta feminista, o modelo prevalecente no contexto da agricultura familiar é o da mulher do lar, que tem suas atividades de trabalho e lazer circunscritas ao lar, sendo pouco valorizadas em consequência disso, de modo a manter as ideologias patriarcais (Nogueira \& Toneli, 2016).

Nesse contexto, conforme Maia e Sant'ana (2011), os papéis de gênero são evidenciados desde a adolescência. Observa-se uma questão notável referente à diferenciação dos papéis de gênero desde essa fase vital: os meninos têm a possibilidade de atingir maior escolaridade e a expectativa de ficarem como herdeiros das propriedades, enquanto as mulheres permanecem no papel de cuidadoras. Além disso, amparados pela religião, a delimitação desses papéis se torna clara: as mulheres são vistas como procriadoras destinadas aos afazeres domésticos e ao cuidado dos filhos e do marido, e os homens trabalham na roça, tidos como provedores do sustento da casa (Lassak, 2010; Pinto et. al., 2013; Nogueira \& Toneli, 2016). Assim, espera-se que as atividades permaneçam e se perpetuem dentro da história familiar nesse cenário rural. Compreende-se que o ambiente e os valores culturais aqui apresentados podem ser fatores importantes para a construção de sentido.

Através da compreensão Logoterapêutica, Frankl (1990) afirma que quando um objetivo de vida de cunho existencial não se realiza, manifestam-se sentimentos de solidão e de vazio. Esses são relacionados ao vazio existencial ou vácuo existencial, terminologia utilizada para retratar os dois sentimentos extremos que coabitam o ser de angústia e tédio (Frankl, 2008). O vazio geralmente é fruto de uma frustração da vontade de sentido, que seria inata a pessoa, considerada como uma motivação primária na vida humana. A liberdade de sentido, como conceito, é uma orientação para a realização de sentido (Studart, 2007). Se, por ventura, a vontade de busca de sentido for frustrada, ocorre o que Frankl definiu como neurose noogênica, uma frustração das necessidades existenciais decorrentes do sentimento de falta de sentido que podem aparecer em sintomas como drogadição, depressão e demais comorbidades psiquiátricas (Silveira \& Gradim, 2015). 
Considerando-se que fatores culturais e modos de vida são ferramentas, segundo Sommerhalder (2010), para a construção de significados e sentidos de vida, mulheres cujos sentidos de vida foram elaborados e alimentados por uma cultura na qual existem apenas para serem mães e esposas podem sofrer psiquicamente. Frankl (1990) traz para reflexão a questão do amadurecimento das mulheres e sua relação com o casamento e a maternidade. Para o autor, ter como único sentido de vida o matrimônio e a maternidade pode se tornar uma idolatria para uma mulher, fazendo-a acreditar ser sua vida sem sentido quando isso não se realiza. Dessa forma, poderá se tornar uma mulher não realizada, tendendo ao desespero e, em casos mais extremos, ao suicídio. Considerando as ideias de Frankl, ousa-se dizer que uma intervenção fundamental nesse contexto seria oferecer outras possibilidades a essas mulheres para encontrarem outros sentidos de vida ou, ao menos, questionarem se o que vivem tem sentido, sem que se sujeitem à idolatria e ao desespero.

Pensando essas mulheres e os valores sociais que auxiliam na busca por sentidos de vida, cabe questionar se o sentido de vida ao ser mãe está atrelado ao destino de ser mulher ou se é uma escolha autêntica dotada de liberdade de escolha frente a sua existência (Xausa, 1986). Frankl (2008), em sua obra, buscou abordar o ser humano como livre em sua autenticidade, tornando-se responsável por sua autoconfiguração, de modo a não ser mero fruto dos condicionantes ambientais que ali são apresentados: "Em suma, é por meio de sua dimensão espiritual que o homem pode objetivar as dinâmicas de condicionamento a que está submetido, na medida em que sua autoconsciência o torna livre para decidir, para tomar uma atitude diante das formas de destino que se lhe apresentam." (Studart, 2015, p. 395).

Frankl (2008) conspirava que a tensão pela busca de sentido mobiliza forças vitais, pois a orientação pela busca de sentido é para a pessoa ${ }^{2}$ algo de sua natureza. Divergindo de autores que veem essa tensão de forma negativa, Frankl acreditava que o ser humano é capaz de mudar a si mesmo diante de todas as mudanças, com uma orientação voltada a busca de sentido, sendo uma alternativa saudável frente aos ocorridos. Assim, afirmava que, de maneira geral, existem três formas de se descobrir um sentido: fazer ou acreditar em algo; viver algo ou amar alguém; ou vivenciar situações desesperadoras. Ou seja, "o sentido como a Logoterapia o entende, é algo bem simples, é uma potencialidade latente em cada situação e que deve ser descoberto" (Xausa, 1986, p. 145). Assim, no decorrer da vida adulta, a busca de sentido é contínua, e considerando o processo de envelhecimento, fase que naturalmente exige maior capacidade de enfrentamento devido às perdas em geral que podem interferir

\footnotetext{
Pessoa: Utilizo aqui uma licença poética, na obra do autor Frankl refere-se sempre ao 'homem' quando retrata o ser humano em si, com a intenção de não oprimir as mulheres que descrevo aqui, lanço mão da palavra pessoa no decorrer da escrita.
}

na vontade de viver, a busca de sentido se mostra como promotora de saúde, pois auxilia no enfrentamento de enfermidades e possíveis adoecimentos nesse momento de vida (Sommerhalder, 2010).

Dessa forma, a Logoterapia vem ao encontro de auxiliar na promoção de saúde e na busca primordial da pessoa por sentidos de vida. A partir da compreensão da literatura e da perspectiva da construção do ser mulher no ambiente da agricultura familiar, pode-se pensar que existem possibilidades de não adoecer quando existe um movimento de autorreflexão e produção de saúde frente a qualquer escolha, desde que sejam atribuídos sentidos para as mesmas. Entende-se que a resposta para o sentido numa perspectiva mais saudável não deve ser criada somente voltada para si, mas a pessoa tem em si uma orientação para a autotranscedência "O ser humano busca, acima de si próprio, algo que não é ele mesmo, um sentido a cumprir ou um outro ser para além de si mesmo" (Xausa,1986, p. 144). Sobre a possibilidade da realização do sentido ser impedida por alguma razão, Frankl (2008) já afirmava que é possível descobrir sentido mesmo diante de adversidades. Sendo assim, os sentidos de vida sempre podem ser ressignificados frente às escolhas diante das situações impostas pela vida. O necessário para que se promova saúde é que as escolhas de sentido não sejam voltadas para dentro de si, mas que sejam autotranscendentes, de si para o mundo, pois é a existência que interroga a pessoa continuamente sobre os sentidos de sua vida (Xausa, 1986).

\section{Mulheres agricultoras: Sobre o trabalho e parentalidade}

No que se refere ao papel político das mulheres na ruralidade, foi somente a partir de agosto de 1994, com o lançamento da cartilha "Nenhuma trabalhadora rural sem documentos", que trazia informações sobre a garantia de seus direitos civis perante o Estado, que o trabalho das mulheres agricultoras foi visto e validado em seus direitos (Salvaro, Lago \& Wolf, 2013). Entretanto, apesar desse marco, o trabalho dessas mulheres ainda é desvalidado, pois são elas que asseguram o bem-estar da família e a reprodução social, e apesar da extensa jornada de trabalho, que implica cuidar da casa e ajudar os cônjuges na lavoura, ainda é um trabalho não reconhecido financeiramente, o que implica no aumento da desigualdade financeira (Costa et. al., 2014). A partir do momento em que surgem políticas públicas que impulsionam um movimento de autorreflexão sobre o papel esperado, como no caso da cartilha, essas mulheres passam a ter á oportunidade de vivenciar uma tensão saudável para a reorientação de sentido (Frankl,2008)

Ainda sobre a renda dessas mulheres, os dados do censo de 2010 do IBGE apontam que na região rural sul o rendimento das mulheres em relação ao total familiar é de apenas 37,3\%. Esse índice corrobora para a afirmação 
das relações de trabalho desiguais, sendo o poder financeiro ou de compra destinado aos homens, fortalecendo a não formalização do trabalho dessas mulheres, bem como a dependência do modelo patriarcal para obtenção de renda (Maia \& Sant'ana, 2011, Pinto et. al., 2013). A ironia desses achados traz a reflexão sobre um modelo predominante sexista, que impulsionou nos anos $1970 \mathrm{a}$ necessidade das vertentes feministas que lutavam pelo reconhecimento das mulheres e igualdade no mercado de trabalho (Pilar, 2013). Essas mulheres, além de trabalharem no meio rural no auxílio de renda familiar, enfrentam a dura "jornada dupla", pois dedicam em média o dobro do tempo que os homens nos afazeres domésticos e reconhecem seu trabalho rural apenas como uma ajuda a seus companheiros (Pinto et. al., 2013).

A função parental também aparece de modo muito peculiar nos dados apresentados pelo IBGE (2006), que aponta que quase dois terços das mulheres rurais são mães entre os 15 e os 21 anos e não utilizam métodos contraceptivos. Tornar-se ou não mãe e esposa é, a priori, para Frankl (1990), uma escolha, não sendo a pessoa vítima de seu destino, mas sim responsável diante de si, pois o destino se dá somente quando tal escolha não é possível, como, por exemplo, vivenciar um desastre natural ou o surgimento de uma doença (Pereira, 2015). Considerando o contexto em que estão inseridas, pode-se considerar que ser esposa e mãe é valorizado pela família e pela comunidade como uma ocupação esperada, apontando para duas questões que mantêm a existência digna, segundo Frankl (1990): ser útil e a consciência de uma tarefa a cumprir. Por isso, para algumas mulheres, ser mãe e casar poderia tornar-se uma escolha nesse contexto considerando que é uma ocupação esperada. Entende-se que essa escolha é tão cultural que em momento nenhum são convidadas a refletirem sobre essa manutenção de papéis, podendo não ser em si uma escolha singular e autêntica a respeito dos lugares que ocupam. Aqui ao pensar sobre esas escolha, conforme Xausa (1986, p. 147), "A vida lhe faz uma pergunta e ao respondê-la tornar-se-á ser responsável”.

Diante dos questionamentos de liberdade e autenticidade de escolha, enquanto os homens recebem heranças de terra, ocupam trabalhos mais rentáveis com possibilidade de poder de investimento, as mulheres só se dedicam a trabalhos rentáveis após o período de escolarização dos filhos, saída deles de casa ou óbito dos cônjuges, isso porque seu dever social é a manutenção dos modelos patriarcais. Assim, observa-se um percentual alto de mulheres que permanecem no meio rural na manutenção de seu status social por meio dos modelos familiares e culturais, alimentando a discrepância salarial na falta de seus direitos garantidos (Maia \& Sant'ana,2011). As mulheres com maior escolaridade dedicam mais horas ao trabalho rentável (IBGE, 2010), o que difere das mulheres rurais, pois de acordo com Maia e Sant'Ana (2011); Salvaro, Lago e Wolf (2013), elas também têm um índice de escolaridade menor que os homens da agricultura familiar. Já as que optam por maior nível de ensino, logo migram para fora deste contexto. Assim, os dados apontam que as perspectivas de escolha parecem limitadas: ou sair, ou ficar na manutenção de um estereotipo cultural. Cabe salientar que a liberdade de escolha pode ocorrer em qualquer uma das opções e ser transformadora de um processo de saúde, porém é necessário que diante disso seja possível tomar consciência deste potencial.

Assim, algumas mulheres, com a intenção de quebrar com os modelos de identificação e diante da sua liberdade de escolha, arriscam uma maior escolaridade migrando para fora do lar (Maia \& Sant'ana, 2011). Esta informação corrobora com os dados do Instituto Brasileiro de Geografia e Estatística (IBGE, 2006), a respeito da agricultura familiar no Brasil, que vem apontando para uma diminuição considerável do número de mulheres em relação ao de homens no cenário rural, aproximadamente 1,5 milhões de homens a mais que mulheres. Conforme os resultados levantados por Maia e Sant'ana (2011), as questões de gênero evidenciam papéis desiguais em funções sociais e de trabalho e renda que podem impulsionar essa saída. Desta forma, visando à diminuição de adoecimento das que optam em ficar, e mesmo aquelas que buscam a saída, é necessário refletir sobre as neuroses coletivas e a autenticidade das escolhas apresentadas. Para Frankl, neurose coletiva seria uma atitude passiva diante do fatalismo apresentado pelo contexto, tornando-se uniforme com a massa, porém, a alternativa diante disso é o questionamento de sua individualidade confrontando um medo à liberdade e assumindo responsabilidade de si (Silveira \& Gradim, 2015).

Para tanto, os sentidos não são meramente criados nem rigidamente estabelecidos; são questionados constantemente de forma singular através de valores criativos, vivenciais e de atitudes, ou seja, através da oferta de um trabalho para o mundo, das experiências afetuosas, da cultura e ambiente, e, por fim, as respostas que se dão perante às dificuldades da vida (Silveira \& Gradim, 2015). Ainda, os valores de atitude, conforme Xausa (1986), "surgem quando fatos irreparáveis e irreversíveis acontecem acima da capacidade humana de superá-los" o que, para Frankl, constituía-se na tríade trágica da dor, da culpa e da morte, é sentir o sofrimento, assumir a responsabilidade e a culpa e entender a finitude da vida. "Pode-se privar a pessoa de tudo, menos da liberdade última de assumir uma atitude alternativa frente às condições dadas" (Frankl, 2008, p. 66-67).

A introdução da Logoterapia como forma de auxílio para promover saúde no ambiente individual acredita, conforme Frankl (2008, p. 135), que "O papel do logoterapeuta consiste em ampliar o campo visual do paciente de modo que todo o espectro de sentido em potencial se torne consciente e visível para ele". Entretanto, considerando as contribuições do autor para movimentos da saúde coletiva, que visam ampliar essas práticas para uma coletivização de demanda, pode-se pensar em espaços 
coletivos construídos com a participação comunitária, juntamente com equipes de saúde que discutam os temas propostos pela logo: autotranscendência, valores de atitude, criativos e vivenciais, vontade de sentido e vazio existencial (Silveira \& Gradim, 2015).

\section{Discussão}

A leitura das obras escolhidas para elaboração das categorias foi de suma importância para entender quem são, hoje, as mulheres presentes na agricultura familiar no Brasil. Os achados apontaram para movimentos culturais permanentes ao longo dos anos que ajudaram a perpetuar estigmas dentro da construção do ser mulher na perspectiva da agricultura familiar, vinculando seu gênero a um papel de reprodução e cuidado do lar. Nesse contexto, a manutenção desses estereótipos colabora para a construção de sentidos de vida voltados para a idolatria, quando a única opção se torna ser mãe e esposa e, consequentemente, sua não realização pode incorrer em vazio existencial, ou seja, grande sofrimento e falta de sentido para essas mulheres.

As oportunidades de ensino, trabalho e lazer são evidentemente diferentes para homens e mulheres, que de acordo com dados levantados nos últimos anos, têm levado a uma maior prevalência de homens neste cenário. Pôde-se verificar, entre as mulheres que migram para fora da agricultura familiar, uma insatisfação com os modelos existentes e a busca por melhores condições de vida. É preciso delimitar que o perfil aqui traçado pode ser diferente em outros contextos, pois sofre influência direta dos aspectos culturais aos quais se encontra submetido. Salienta-se o período histórico dos materiais selecionados foi dos anos de 2011 a 2016 não limitando-se a Estados brasileiros específicos, o perfil traçado pode sofrer pequenas variações de acordo com a diversidade cultural da agricultura familiar.

Consideradas como detentoras de tamanho poder, pois são elas as responsáveis pela manutenção da agricultura familiar, ainda que tal poder tenha pouco reconhecimento, observa-se a necessidade de questionar essas mulheres frente a suas escolhas e responsabilidades. A permanência na vida do campo não precisa ser dotada de frustração existencial, pois conforme Silveira e Gradim (2015), "a Logoterapia, especificamente, enfoca a atitude do paciente diante do problema”, podendo, assim, vir a ser um instrumento favorável para a promoção de saúde especificamente nesse contexto, pois ajudaria essas mulheres a lançarem um olhar para a autotranscendência, para além de seu cotidiano, auxiliando na busca por novos sentidos de vida. Para Xausa (1986), a Logoterapia tem muito a contribuir no campo da saúde mental, pensando os efeitos das perdas de sentido e evitando a formação de neuroses noogênicas; na área da psicologia social, refletindo em como o sentido pode ser gerador de mudança social no contexto de pessoas de países subdesenvolvidos. No caso dessas mulheres, a aplicação da Logoterapia pode ter um potencial libertador ao oportunizar reflexões e a busca de novos sentidos.

\section{Considerações finais}

Os temas aqui abordados foram fruto de uma pesquisa bibliográfica com a intenção de relacionar a construção do ser mulher na agricultora familiar, tecer luz sobre este assunto pelo viés da Logoterapia, e, desta forma, possibilitar a reflexão sobre essas temáticas. Após a pesquisa foi possível delimitar o perfil dessas mulheres em duas categorias: "Ser mulher: uma construção autoral ou um destino a cumprir" e "Mulheres agricultoras: sobre trabalho e parentalidade". A primeira retrata como ser mulher na agricultura familiar está relacionado com matrimônio e reprodução. Já a segunda traz dados importantes para visualizar o cenário de trabalho destas mulheres. A priori, poderia se criar apenas uma categoria, pois ser mulher é dotado da função de cuidar dos maridos e filhos, porém considerando que é um trabalho, foram mantidas as duas categorias com a intenção de não oprimir essas mulheres e reforçar a importância de se olhar sobre seus modos de viver.

Este estudo não tem por intenção desconstruir a agricultura familiar. A partir dele, pretende-se fundamentalmente vislumbrar alternativas de construção de saúde frente ao cenário atual dessas mulheres, buscando alternativas de, primeiramente, compreendê-las para articular intervenções potentes de sentido. Nota-se, como de vital relevância para a perpetuação das mulheres na agricultura familiar, a importância das mulheres nesse contexto. Entretanto, são questionados modelos que estejam persistindo no enfraquecimento e adoecimento das mesmas. A Logoterapia vem no auxílio de questionar essas escolhas autênticas e, assim, permitir um fortalecimento diante da autotranscedência e do manejo frente às possibilidades.

Como alternativas para produzir saúde diante do contexto da agricultura familiar, sugere-se fortalecer o diálogo sobre a Logoterapia e a resiliência, fundamentais ao processo de saúde, uma vez que "a resiliência torna-se a operacionalização de algumas das consequências de se encontrar o sentido da vida" (Silveira \& Mahfoud, 2008, p. 575). Arrisca-se, assim, mais um aliado aos movimentos da luta por empoderamento e produção de saúde em diversos cenários. Ademais, pesquisas empíricas poderiam ser de grande valia na produção de material sobre esta temática, já que não existem pesquisas disponíveis na literatura, assim possibilitando visibilidade a essas mulheres. A aplicação de intervenções também auxiliaria a validar as contribuições da Logoterapia no contexto rural e no trabalho com mulheres. 


\section{Referências}

Bardin, L. (2009). Análise de conteúdo. Lisboa: Edições 70.

Cavalcante, R. B., Calixto, P. \& Pinheiro, M. M. K. (2014). Análise de Conteúdo: Considerações Gerais, relações com a Pergunta de Pesquisa, Possibilidades e Limitações do Método. Inf \& Soc.: Est., 24 (1), 13-18.

Costa, M. G. S. G., Dimenstein, M. D. B. \& Leite, J. F. (2014). Condições de vida, gênero e saúde mental entre trabalhadoras rurais assentadas. Estud. psicol. (Natal), 19 (2), 145-154. doi: 10.1590/S1413-294X2014000200007.

Correa, W. H. \& Holanda, A. F. (2012). Prostituição e sentido de vida: relações de significado. Psico-USF, 17 (3) 427-435. doi: 10.1590/S1413-82712012000300009.

Faria, N. M. X. et. al. (1999). Estudo transversal sobre saúde mental de agricultores da Serra Gaúcha (Brasil). Rev. Saúde Pública, 33 (4), 391-400. doi: 10.1590/S0034-89101999000400011.

Frankl, V. E. (2008). Em busca de sentido. Petrópolis: Vozes.

Frankl, V. E. (1990). Psicoterapia para todos. Petrópolis: Vozes.

Geiger, L. (2014). Aprendendo a ser mulher: contribuições de uma educação holística por meio dos círculos femininos Tenda da Terra e Tenda da Lua. (Dissertação de Mestrado, Pontifícia Universidade Católica do Rio Grande do Sul, Porto Alegre) < http://tede2.pucrs.br/tede2/bitstream/tede/3802/1/457559.pdf $>$.

Gonçalves, M. M. D. C. F., Melo, A. d. S., \& Vital, T. W. (2014). Estudo de casos de agroindústria da agricultura familiar em Pernambuco. Universidade Federal Rural de Pernambuco.

Brasil. Instituto Brasileiro De Geografia E Estatística- IBGE. Estimativas (2006). São Paulo: IBGE.

Brasil. Instituto Brasileiro De Geografia E Estatística- IBGE. Estimativas (2010). São Paulo: IBGE.

Kraus, T., Rodrigues, M. \& Dixe, M. A. (2009). Sentido de vida, saúde e desenvolvimento humano. (Portuguese).: Meaning of life, health and human development. (English). Revista de Enfermagem Referência, 10, 77-88.

Lassak, S. (2010). Lutando por terra e vida! (Portuguese).: fighting for land and life. (english). Teocomunicação, 40 (2) 238-280.

Maia, A. H. \& Sant'ana, A. L. (2011). Vivências e projetos das jovens rurais: um olhar sob a sua condição de mulher na agricultura familiar e a relação com suas estratégias de vida. (Dissertação de Mestrado, Universidade Estadual Paulista (UNESP), Ilha Solteira) < http://bdtd.ibict.br/vufind/Record/ UNSP_86c3151dd2ffdaff27b691db56f56c27>.

Mota, G. R. \& Souza, R. T. (2013). Responsabilidade: sobre a consciência moral e a alteridade no pensamento de Viktor Frankl e Emmanuel Levinas. (Dissertação de Mestrado, Pontifícia Universidade Católica do Rio Grande do Sul, Porto Alegre) <http://repositorio.pucrs.br/dspace/bitstream/ 10923/5601/1/000453071-Texto\%2bCompleto-0.pdf>.

Pereira, I. S. (2007). A vontade de sentido na obra de Viktor Frankl. Psicologia USP, 18 (1), 125-136.
Pereira, I. S. (2015). Espírito e liberdade na obra de Viktor Frankl. Psicol. USP, 26 (3), 390-396. doi: 10.1590/0103656420140036 .

Pilar, J. A. \& Ernst, A. (2013) Ser mulher: O sujeito do desejo na fronteira entre o sagrado e o profano. (Tese de Doutorado, Universidade Católica de Pelotas, Pelotas) <http://bdtd. ibict.br/vufind/Record/UCPe_f5418cdcb962cc5104512d1ec1052aa3>

Pinto, N. M. A., Pontes, F. A. R. \& Silva, S. S. C. (2013). A rede de apoio social e o papel da mulher na geração de ocupação e renda no meio rural. Temas psicol. 21 (2), 297-315. doi: 10.9788/TP2013.2-01.

Pinto, V. C. et. al. (2005). Identidade feminina, família e profissão: a experiência de ser mulher na contemporaneidade. (Dissertação de Mestrado, Universidade Católica de Pernambuco, Recife) <http://bdtd.ibict.br/vufind/Record/UCAP_6eee7f7 fdbb84979b4b1af54db369fab>.

Rogers, N. (1993). A Mulher Emergente: uma experiência de vida. São Paulo: Martins Fontes.

Salvaro, G. I. J., Lago, M. C. S. \& Wolff, C. S. (2013). "Mulheres agricultoras" e "mulheres camponesas": lutas de gênero, identidades políticas e subjetividades. Psicol. Soc., 25 (1), 79-89. doi: 10.1590/S0102-71822013000100010.

Silveira, D. R. \& Mahfoud, M. (2008). Contribuições de Viktor Emil Frankl ao conceito de resiliência. Estud. psicol. (Campinas), 25 (4), 567-576. doi: 10.1590/S0103166X2008000400011.

Silveira, D. R. \& Gradim, F. J. (2015). Contribuições de Viktor Frankl ao movimento da saúde coletiva. Rev. abordagem gestalt., 21 (2), 153-161.

Sommerhalder, C. (2010). Sentido de vida na fase adulta e velhice. Psicologia: reflexão e crítica, 23 (2), 270-277.

Veras, A. S. \& Rocha, N. M. D. (2014) Production of papers about Logotherapy in Brazil from 1983 to 2012. Estud. pesqui. psicol., 14 (1), 355-374.

Xausa, I. A. M. (1986). A psicologia do sentido da vida. Petrópolis: Vozes.

Franchesca Carolina Baronio - Possui graduação em Psicologia pela Faculdade de Desenvolvimento do Rio Grande do Sul. Email: franbaronio@gmail.com

Luciene Geiger - Graduada em Psicologia pela Universidade Federal do Rio Grande do Sul, Mestre em Educação pela Pontifícia Universidade Católica do Rio Grande do Sul, com Especialização Clínica em Psicoterapia Centrada na Pessoa (Delphos Instituto de Psicologia), Pós-Graduação em Psicologia Transpessoal (UNIPAZ-SUL e FISUL) e Acupuntura (ABACO/CESCIS e Faculdades São Judas Tadeu - RJ). Atualmente é docente e supervisora em Psicologia na Escola de Saúde e Bem-Estar da Faculdade de Desenvolvimento do Rio Grande do Sul (FADERGS).

Recebido em 15.12.2016

Primeira Decisão Editorial em 08.08.2017

Aceito em 06.09.2017 